\title{
MistuRe: Uma Plataforma para Unificação de Dados Científicos sobre Compatibilidade de Produtos em Misturas de Tanque com Calda Herbicida
}

\author{
César Henrique Marçal Cardoso ${ }^{1}$, Edson Aparecido dos $\operatorname{Santos}^{2}$, Rafael Dias Araújo ${ }^{1}$ \\ ${ }^{1}$ Faculdade de Computação - Universidade Federal de Uberlândia (UFU) \\ Monte Carmelo - MG - Brasil \\ ${ }^{2}$ Instituto de Ciências Agrárias - Universidade Federal de Uberlândia (UFU) \\ Monte Carmelo - MG - Brasil \\ ceshen.marcal@gmail.com, edsonsantos@ufu.br, rafael.araujo@ufu.br
}

\begin{abstract}
Farmers, agronomists, specialized professionals, and several other stakeholders in the agronomic area lack an aggregate, reliable and free source of information about compatibility of phytosanitary products. Regarding this problem, this work presents a platform that unifies results and scientific information regarding product compatibility in tank mixing of herbicide solutions. The platform was developed using modern technologies and its first version has in its database 224 combinations among the 990 commercial products available in Brazil, all of them herbicides.
\end{abstract}

Resumo. Produtores rurais, engenheiros agrônomos, profissionais especializados e vários outros atuantes da área agronômica carecem de uma fonte agregada, confiável e gratuita a respeito da compatibilidade de produtos fitossanitários. Em vista desse problema, este trabalho apresenta a criação de uma plataforma que unifica resultados e informações científicas a respeito da compatibilidade de produtos em misturas de tanque com calda herbicida em um software. A plataforma foi desenvolvida utilizando tecnologias atuais e a sua primeira versão já conta em sua base de dados com 224 combinações entre os 990 produtos comerciais disponíveis no Brasil, todos estes, herbicidas.

\section{Introdução}

O controle químico consistido na utilização de produtos fitossanitários, também chamados de agrotóxicos, é a principal e mais difundida técnica para proteção das plantas contra populações danosas de insetos, microrganismos ou plantas daninhas. O Brasil é o maior consumidor de agrotóxicos do mundo, além de existirem milhares de produtos no ministério da agricultura [AGROFIT 2021]. Uma vez que o manejo incorreto dessas substâncias levam a problemas fitossanitários que podem inviabilizar a produção comercial de alimentos do mundo [Chaves et al. 2013, Andrew et al. 2015, Westwood et al. 2018], é de suma importância que a combinação desses compostos químicos produzam resultados positivos.

$\mathrm{O}$ ato de misturar corretamente tais substâncias promove uma série de benefícios como a otimização do tempo, economia de recursos financeiros, equipamentos, água, etc [Gazziero 2015]. Porém, existe a ausência de uma plataforma de software que seja 
capaz de compor uma grande base de dados a respeito de misturas de produtos químicos utilizados na agricultura, e disponível de forma gratuita. Por exemplo, o TankMix ${ }^{1}$ e o Koppert $\mathrm{App}^{2}$ são plataformas proprietárias que recomendam somente a combinação de produtos da empresa e não apresentam referências científicas. Assim, a partir desta necessidade, surgiu o objetivo deste trabalho que consiste no projeto e desenvolvimento de uma plataforma de software capaz de promover aos seus usuários finais o acesso a informações científicas sobre a compatibilidade desses produtos, unificando os resultados disponibilizados em indexadores científicos conhecidos em uma única aplicação.

\section{Funcionalidades}

A plataforma aqui apresentada integra um Sistema Web e um Aplicativo Mobile (desenvolvido para os sistemas operacionais Android e iOS). Os atores envolvidos são: Administrador, Pesquisador, Avaliador e Usuário Final (Produtores rurais, engenheiros agrônomos, profissionais especializados e estudantes da área). A Figura 1 mostra uma visão geral das funcionalidades e atores por meio de um Diagrama de Casos de Uso.

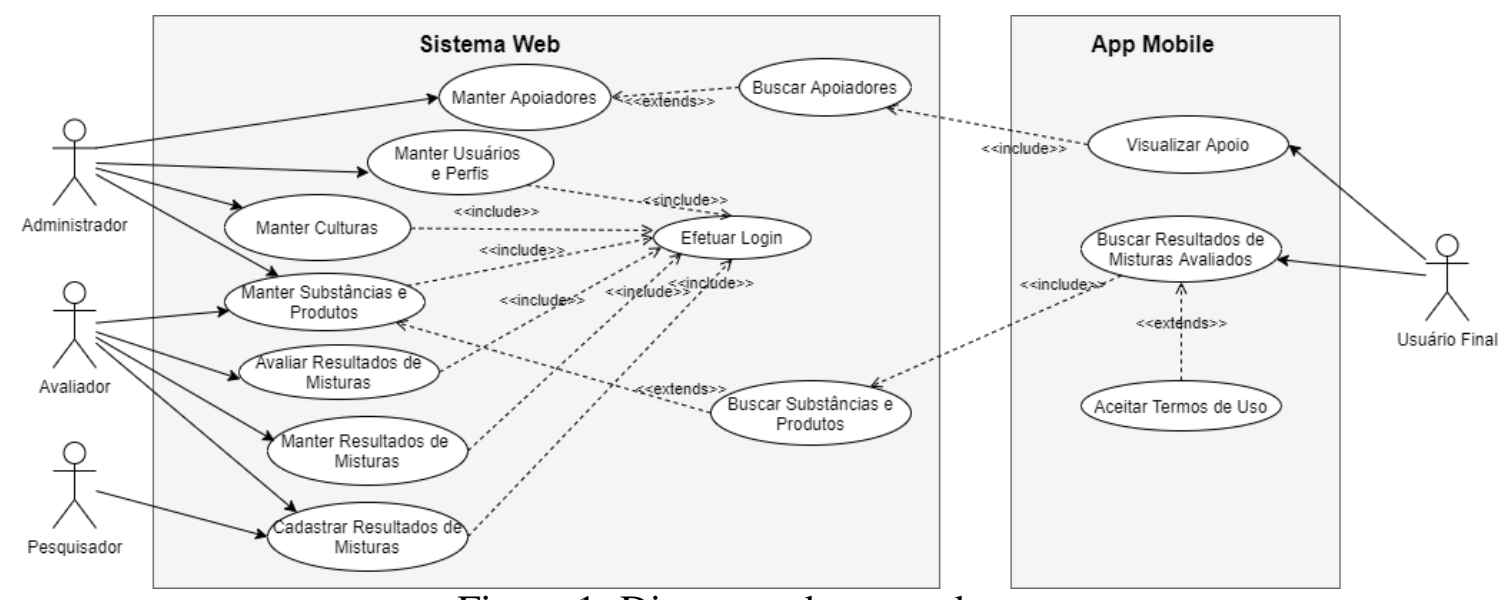

Figura 1. Diagrama de casos de uso.

Dentre as funcionalidades, é possível efetuar o cadastro de pesquisadores e avaliadores. Os pesquisadores são os responsáveis por popular a base de dados, analisando artigos científicos que versam sobre misturas fitossanitárias. Já os avaliadores são responsáveis por moderar os dados inseridos pelos pesquisadores, aprovando ou rejeitando as referências científicas sobre misturas cadastradas como forma de assegurar a qualidade das publicações selecionadas pelos pesquisadores. O motivo da moderação é garantir que o entendimento do pesquisador está correto por meio de uma checagem dupla. As misturas são combinações de duas ou mais substâncias (que eventualmente podem ter nomes comerciais), juntamente com suas respectivas dosagens, cultura em que os experimentos foram realizados, links para as referências científicas e a conclusão obtida no respectivo trabalho. O administrador é responsável por manter a base de usuários, culturas (por exemplo, soja, trigo, milho etc.) e apoiadores que serão exibidos tanto no sistema Web quanto no aplicativo mobile (que podem ser parceiros públicos ou privados).

O primeiro passo do processo de busca de misturas pelo aplicativo, é a criação de uma combinação dois ou mais produtos, como mostrado na Figura 2, que pode ser feito

\footnotetext{
${ }^{1}$ https://www.yarabrasil.com.br/nutricao-de-plantas/solucoes-digitais/tankmix/

${ }^{2}$ https://www.koppert.com.br/aplicativo-de-compatibilidade-de-produtos/
} 
pesquisando pelo princípio ativo de uma substância, como Glyphosate ou Fluazifop-Pbutyl, por um de seus nomes comerciais, como Baris ou Robust, ou através de apelidos ou nomes populares dos produtos como "Glifosate". Após selecionar ao menos dois produtos, basta clicar no botão "Pesquisar" para que os resultados sejam listados em sequência, exibindo, de forma resumida e objetiva, as principais informações sobre a mistura procurada pelo usuário, como mostra a Figura 3. Mais detalhes sobre os resultados são exibidos em uma outra tela (Figura 4) alcançada a partir de um clique na mistura, na qual também contém o link para o artigo científico em que o resultado listado se baseia. Um vídeo demonstrativo pode ser encontrado em: https: / / youtu.be/rrmNm1L5wio.

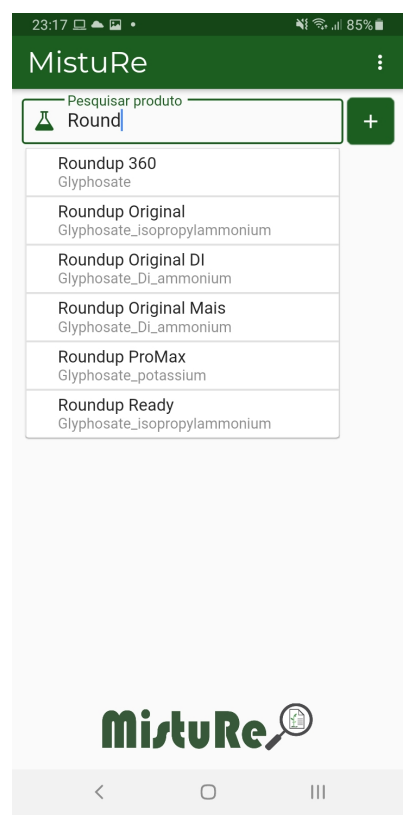

Figura 2. Busca de misturas.
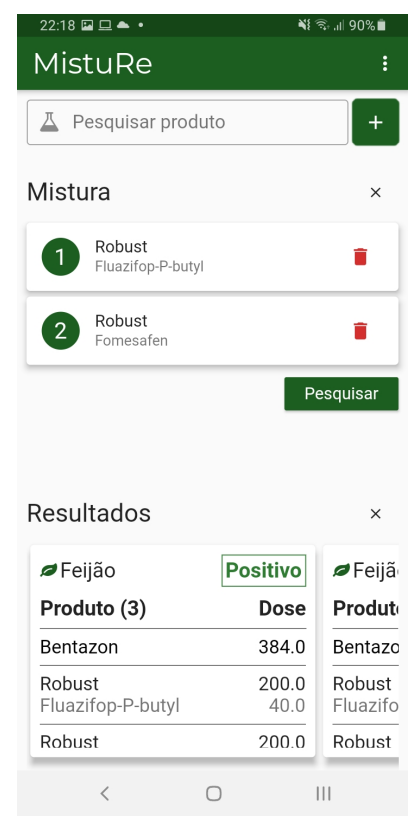

Figura 3. Visualização dos resultados cadastrados.

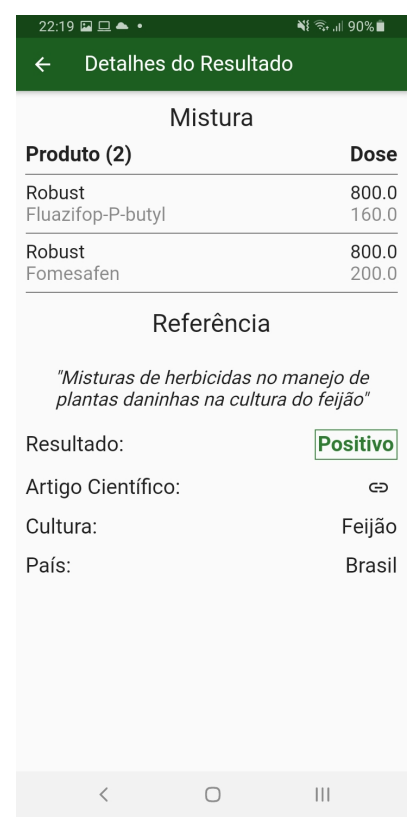

Figura 4. Visualização de mais detalhes do resultado.

\section{Resultados Preliminares e Discussões}

As tecnologias utilizadas para desenvolvimento do sistema Web foram HTML5, CSS3, jQuery e PHP. O aplicativo mobile foi construído utilizando a linguagem de programação Dart (https://dart.dev), juntamente com o framework Flutter (https:// flutter.dev), que é o kit de desenvolvimento de aplicativos da empresa Google. Além disso, foi utilizado o sistema gerenciador de banco de dados MySQL, e o modelo de dados projetado foi refinado em diversas iterações no decorrer do projeto para representar um melhor mapeamento das principais entidades do sistema.

Na primeira versão da aplicação, consta um total de 127 produtos técnicos (herbicidas) e 890 produtos comerciais. Além disso, a partir de 53 artigos científicos publicados, foram mapeadas 227 combinações entre as substâncias disponíveis, na qual apenas 59,8\% dos produtos técnicos estão presentes em alguma dessas combinações. Ademais, apenas 4,3\% dos produtos comerciais disponíveis estão presentes em alguma mistura, demonstrando que ainda existe muito trabalho a ser feito. Após finalizar o desenvolvimento da primeira versão do aplicativo, foi realizado um teste exploratório de aceitação e uso com 25 pessoas da área de agronomia (professores agrônomos, alunos de graduação e produtores rurais), representando o público-alvo da aplicação. Resultados mostraram uma boa 
aceitação do aplicativo com a recomendação de uso para colegas de trabalho. Além disso, houve vários elogios e comentários a respeito do impacto positivo que o uso da aplicação proposta pode promover à agricultura/agronegócios em geral.

Em vista de fatores que enaltecem o potencial da aplicação e seu caráter inovador, principalmente, pela capacidade de suprir uma necessidade bastante pertinente no campo aliado à grande aprovação do público-alvo da aplicação, a equipe idealizadora do projeto foi motivada a realizar o registro do software no Instituto Nacional de Propriedade Industrial (INPI) - Registro $\mathrm{n}^{\mathrm{o}}$ : BR512021000187. Também foi efetuado um pedido de registro de marca que está em análise. Existe um potencial de parcerias com entidades públicas e privadas para ensino e também como apoio à tomada de decisões estratégicas e gerenciais. No caso de parceria privada, é possível haver uma exploração de mercado junto a empresas da área para o fornecimento de dados ou até mesmo customização da aplicação para seus produtos e análise de dados. Além disso, a plataforma pode ser utilizada como ferramenta de apoio científico a pesquisadores para identificação de lacunas de pesquisa.

\section{Considerações Finais}

Este artigo apresentou a plataforma de software chamada de "MistuRe", que contém um sistema Web e um aplicativo para dispositivos móveis que reúne dados científicos sobre os resultados de misturas de tanque com calda herbicida. Resultados preliminares de usabilidade mostraram uma boa aceitação da proposta pelos usuários, que ressaltaram o potencial de impacto à área de agricultura/agronegócios. O trabalho resultou em um registro de software e de marca junto ao INPE. Como trabalhos futuros, pretende-se criar mecanismos automatizados de recuperação da informação para auxiliar o pesquisador na busca dos trabalhos científicos, aumentar a base de dados de misturas e utilizar técnicas de visualização da informação para criar uma área de análises para os pesquisadores.

\section{Agradecimentos}

Os autores agradecem o apoio do CNPq e da UFU para a realização deste trabalho.

\section{Referências}

AGROFIT (2021). Banco de informações sobre os produtos agroquímicos fitossanitários registrados no Ministério da Agricultura, Pecuária e Abastecimento (MAPA). Disponível em: http: / / agrofit.agricultura.gov.br. Último acesso em: 19/03/2021.

Andrew, I. K. S., Storkey, J., and Sparkes, D. L. (2015). A review of the potential for competitive cereal cultivars as a tool in integrated weed management. Weed Research, 55(3):239-248.

Chaves, M. S., Martinelli, J. A., Wesp-Guterres, C., Graichen, F. A. S., Brammer, S. P., Scagliusi, S. M., Silva, P. R., Wiethölter, P., Torres, G. A. M., Lau, E. Y., Consoli, L., and Chaves, A. L. S. (2013). The importance for food security of maintaining rust resistance in wheat. Food Security, 5:157-176.

Gazziero, D. (2015). Misturas de agrotóxicos em tanque nas propriedades agrícolas do Brasil. Planta Daninha, 33:83-92.

Westwood, J. H., Charudattan, R., Duke, S. O., Fennimore, S. A., Marrone, P., Slaughter, D. C., Swanton, C., and Zollinger, R. (2018). Weed management in 2050: Perspectives on the future of weed science. Weed Science, 66(3):275-285. 